\begin{tabular}{|c|c|}
\hline & Asian Social Work Journal (ASWJ) \\
$\substack{\text { ASIAN SOCIAL WORK } \\
\text { JOUNAL } \\
\text { (ASW) }}$ & Volume 4, Issue 4, October 2019 \\
& e-ISSN : 0128-1577 \\
& Journal home page: \\
& www.msocialwork.com \\
\hline
\end{tabular}

\title{
Social Work Intervention with Women Offenders: A Pathway to Prevent Recidivism
}

\author{
Mangala Honawar ${ }^{1}$ \\ ${ }^{1}$ Tata Institute of Social Sciences, India \\ Corrrespondence: Mangala Honawar (mangala.honawar1@gmail.com)
}

\begin{abstract}
Literature has consistently shown that women offenders often have unique needs compared to men primarily due to their role as primary care givers within the family structure. The challenges and needs of women offenders vis-à-vis their vulnerabilities, biases against them, discriminations at various levels and of various kinds in the society and several such factors demand both a professional and a holistic approach towards preventing recidivism among them. Over a period, there has been a growing need for specialized interventions for various populations of people in conflict with law. For example, there is a growing area of intervention for specific categories such as juvenile offenders, young offenders, etc. The statistics on crime show an increasing involvement of women in crime and an emerging need to deal with the issue differently than the existing approach of the Criminal Justice System. It is in this context that professional social workers have an important role to play in prison settings, particularly in the context of women, their vulnerabilities and their involvement in crime. They can intervene during crucial phases such as when the women enter the prison for the first time, during their under-trial detention, conviction period and also provide family related services, health and mental health support and counseling, educational support, facilitate skill development, and job placement in addition to monitoring prison conditions. Social work intervention holds the potential to prevent recidivism among women offenders.
\end{abstract}

Key words: prison, recidivism, social work, women offenders

\section{Introduction}

The distinct differences between the lives of women and men shape their patterns of criminal offending. Empirical evidence indicates that victimization, economic marginalization, and substance abuse disproportionately affect women and play unique roles in shaping female criminality (Daly, 1998; Owen, 1998; Chesney-Lind, 1997; Belknap, 1996;). Researchers have documented gendered pathways to crime and imprisonment (Belknap, 2007; Bloom et al., 2003; Daly, 1998; Owen, 1998; Chesney-Lind, 1997; Daly and Chesney-Lind, 1988).

Women in prisons have needs that are quite different from men, resulting in part from women's disproportionate victimization from sexual or physical abuse and in part from their responsibility for children. Women offenders are also more likely than men to have become addicted to drugs, to have mental illnesses, and to have been unemployed before incarceration (Morash, Bynum, and Koons, 1998)

According to a study by the National Institute of Justice (1998): 
- More than 43 percent of women inmates (but only 12 percent of men) said they had been physically or sexually abused before their admission to prison.

- Women serving a sentence for a violent offense were about twice as likely as their male counterparts to have committed their offense against someone close to them.

- More than two-thirds of all women in prison had children under the age of 18 , and among them only 25 percent (versus 90 percent for the men) said their children were living with the other parent.

These different circumstances, together with the general rise in the number of women in prisons, point to the need for different intervention approaches and programming to ensure gender justice and to provide pathways that reduce recidivism (National Institute of Justice, 1998).

\section{Women in Criminal Justice System}

Statistics from across the world reflect the steady growth in the involvement of women in crime. More than one million women are currently under the supervision of the criminal justice system in the U.S. More than 200,000 of these women are confined in state and federal prisons or local jails. Expanding at 4.6 per cent annually between 1995 and 2005, women now account for 7 per cent of the population in state and federal prisons. The number of women in prison has increased at nearly double the rate of men since 1985 to 2007, 404 per cent vs. 209 per cent (The Sentencing Project, 2007).

Most women in the criminal justice system are poor, uneducated, and unskilled, and they are disproportionately women of color. Many come from impoverished urban environments and were raised by single mothers or in foster homes. Women are more likely than men to have committed crimes to obtain money to purchase drugs. Although it is widely assumed that female addicts typically engage in prostitution as a way to support a drug habit, it is more common for these addicts to engage in property crimes (Sanchez and Johnson, 1987).

The women's prison population in England and Wales more than doubled between 1995 and 2010 from under 2,000 women to over 4,000 and declined to 3821 in April 2016. But the UK still has one of the highest rates of women's imprisonment in Western Europe. The number of women recalled to prison rose dramatically after commencement of the Offender Rehabilitation Act 2014, which introduced post-custody supervision for people serving sentences of less than 12 months as they breached the conditions of their license whilst under supervision on release (Prison Reform Trust, 2017).

Out of the total crimes in India, about 5.1 per cent females were arrested and accused of committing crimes (Crime in India, 2016). An increasing trend in the female criminality has been found considering their involvement in total cognizable crimes has increased from 3.1 percent in 1990, to 4.1 percent in 1995 to 4.7 percent in 1996 to 5.8 percent in 2006 to 6.2 percent in 2010 to 10.2 per cent in 2014 to 4.9 per cent in 2015 . This shows that the percentage has tripled in the last 20 years especially in cities from 1990 to 2014. Only in 2015, the percentage of women's involvement in crime has drastically decreased to 4.9 percentage from 10.2 per cent which is an unusual trend.

While there is no clear data on the percentage of recidivism among women, the author's experience shows that nearly one fourth of women in prison were arrested more than once. The growing involvement of women in crime demands special attention from the Criminal Justice System, particularly considering the context, conditions and the experiences of women per se. There is an urgent need to place them under a specialised category as far as intervention is concerned and social work interventions in particular need to be tailored likewise. 


\section{Studies on Factors Fostering Recidivism}

The socio-economic as well as demographics of the environment of an individual who indulges in crime becomes a critical determinant as far as the question of his re-indulgence in crime is concerned. Studies conducted across countries have identified various factors that are key determinants fostering recidivism.

A study by La Vigne et al. (2004) found that inmates who return to disadvantaged neighbourhoods are less likely to find employment and are more likely to reoffend. Even when controlling for offender and offense characteristics such as age, sex, prior arrest and incarceration history, and property versus personal offenses, Baumer et al. (2003) found that the likelihood of re-arrest is greater among inmates released to areas that are more densely populated and that have higher income inequality (cited in Leverentz 2006).

A study conducted by Teneng and Abadi (2018) reveals that the main contributing factors for recidivism were economic problems like poverty, lack of income, unemployment and poor living conditions, because this study found that most of the prisoners do not have job and enough income before and after imprisonment. Besides, family problems like lack of close supervision and guidance, lack of love and affection from parents, divorce or separation, and death of one or both parents are other pushing factors for recidivists to re-offend. Moreover, their current study indicates psychological problems (i.e. anxiety, depression, addiction, aggressive personality traits) and labeling, discrimination and marginalization, false witnesses and peer pressure are the main causes of re-offending. Lack of classification and over overcrowding of correctional centers, lack of adequate rehabilitation and reintegration services are other factors contributing for recidivism.

\section{Issues Faced by Female Offenders}

The studies quoted earlier are reflective of a more general offender population. However, when it comes to the factors fostering women, there are certain specific concerns and issues that need to be attended to.

Policymakers and correctional officials planning for and providing gender-responsive services for female offenders need to consider two main concerns: (1) the role of motherhood and (2) the interrelationship between substance abuse, trauma, and mental health issues.

\section{The role of motherhood}

A major difference between female and male offenders involves their relationships with their children. For many incarcerated mothers, their relationships-or lack thereof-with their children can profoundly affect how they function in the criminal justice system. Often, behaviours such as negativism, manipulation, rule breaking, and fighting among incarcerated women are signs of what Garcia Coll et al. (1998) have described as "resistance for survival" in response to the grief, loss, shame, and guilt these women feel about their roles as mothers.

\section{Substance abuse, trauma, and mental health issues}

Looking at the profile of women in the system, the differences between women and men, and the concept of level of burden reveals three critical and interrelated issues in women's lives: substance abuse, trauma, and mental health. These issues affect female offender's transition back into the community in terms of both programming needs and the success of re-entry. In terms of substance abuse, female offenders are more likely to have used drugs (e.g., cocaine and heroin), to have used them intravenously, and to have used them more frequently before being arrested. Women are also more likely to have a co-existing psychiatric disorder and to exhibit lower self-esteem (Bloom and Covington 2000). 
In the Indian context, the role of motherhood is coupled with intense psychological and physical neglect when they spend time in jail. This is further aggravated by social stigma post their release, making re-integration into the world outside the prison highly challenging. Family ties are often lost, leaving the women isolated, at times abandoned as well and that is when even hand to mouth survival becomes an issue pushing women in a vicious cycle of survivors to victims to offenders.

These issues demand professional attention at multiple levels and that is where social work intervention plays a key role. The need of the hour for the women is assistance to help them deal with problems they face in prisons, challenges they face with regard to weak family ties and contact with children and support for rehabilitation post release.

\section{Social Integration of Offenders: A Need}

The rehabilitation of offenders and their successful social reintegration into society should be both among the basic objectives as well an integrated process in the criminal justice systems. Rule 61 of the United Nations Standard Minimum Rules for the Treatment of Prisoners (1955) revised and adopted as Nelson Mandela Rules and the Standard Minimum Rules for the Treatment of Prisoners and Rule 1.5 of the United Nations Standard Minimum Rules for Non-custodial Measures (the Tokyo Rules) clearly acknowledge this point and emphasize the importance of interventions to support the $\mathrm{s}$ social reintegration of offenders as a means of preventing further crime and protecting society.

The primary objective of social reintegration programmes is to provide offenders with the assistance and supervision that they may need to desist from crime, to successfully reintegrate into the community and to avoid a relapse into criminal behaviour. In general, there are three main categories of social reintegration programmes: (a) prison-based rehabilitation programmes; (b) reintegration and aftercare programmes delivered upon release; and (c) non-custodial, community-based programmes. In many countries, renewed emphasis is being placed on managing the re-entry of offenders into society. Reentry support typically occurs at the end of a period of imprisonment, but it can also occur earlier as part of a conditional release programme, with or without formal supervision. (UNODC, 2018).

The Model Prison Manual 2016 recognises that the provision of meaningful and gainful employment is the state's responsibility and the right of prisoners. The assumption here is that gainful work would not only help correct the psyche of offenders, but also help them develop as responsible citizens with a respectful attitude towards society (Ministry of Home Affairs, Government of India, 2016).

In India, the concept of reform and rehabilitation in prisons is limited to work in prison industries, which the prisoner is forced to undertake to earn the minimum wages. Due to overcrowding, very few prisoners are able to get wage work inside the prisons and to be fair the prison officials give work in turns so that all prisoners get a chance to work and earn wages. While this does fulfil some objectives of the social re-integration, like leading a disciplined life and learning team work and co-operation among others, it is largely limited to rendering hard job skills which may be out dated in the job market and does not really prepare them for a social life after release.

As per the Prison Statistics India Report (NCRB, 2016), 4.4 per cent of the prisoners are females compared to 95.6 per cent males. The situation of women prisoners is worse than men when it comes to wage work as there are hardly any industries in the women's section. Women are involved in typical jobs like cleaning the grains, cutting vegetables, sweeping and cleaning cells, stitching, etc. may not equip them with skills to find jobs after leaving the prison. These factors, combined with the relative isolation of many inmates from their families, mean that women prisoners often leave prison with no place to go.

But in the existing scenario of steadily increasing crime rates among women, which is likely to result in increasing rates of recidivism in the days to come, it is crucial that re-integration moves beyond just wage work in prison. There is a need for the Criminal Justice System to adopt a more holistic and comprehensive approach to address issues related to rehabilitation and re-integration of women 
offenders. By virtue of their heightened levels of vulnerability, women require to be treated with special consideration and attention. Therefore, the interventions need to be tailored in a way that would facilitate a successful re-entry in society and prevent recidivism among women offenders.

\section{Background to the Study}

The author conducted a study on recidivism among women offenders in Mumbai city as part of her doctoral work. In the field of studies on criminality, crimes against women have largely been the focus. However, 'women' as a category in crime, the perceptions, experiences and factors that fostered their entry into crime and their agency to get out of the cycle of recidivism, have received little attention. But the formulation of intervention strategies to address the issue of female criminality does require a comprehensive understanding of the various dimensions of the issue.

The researcher focused on understanding the factors influencing recidivism in women, using an exploratory and qualitative research design. The universe of this study consisted of female offenders in the city of Mumbai and its suburbs, especially those with a history of more than one arrest. The women belonged to most age groups above 18 years, with the possibility of their first arrest being before they turned 18, i.e., when they were arrested as children in conflict with the law. Using the purposive sampling method, in-depth interviews were conducted with 20 women repeat offenders, over a period of 24 months, from 2013 to 2015.

\section{Findings}

\section{Profile of Women Recidivists}

Most women recidivists belonged to lower middle-class families, had very low levels of education and limited skill sets. Majority of the women shouldered the responsibility of being the primary caregiver of the family in the absence of their husbands or when the husband/ partner was dependent on the income of the woman.

\section{Previous Attempts at Employment}

The women had explored various work options that were legal and not so legal, before turning to crime as a means of income. Some of these options were working in beer bars or as sex workers in red light areas. But the women found it very difficult to sustain themselves in either of the categories of work. Legal work entailed fixed hours of work, away from home and fetched less money at the end of the month. The fear of raids both in beer bars and red light areas, prompted their husbands/partners or their families to ask the women to shift to any other areas of work. This pressure to shift, along with the expectation that the woman fulfills her domestic responsibilities while continuing to be the bread winner of the family, gradually compelled the women towards crime.

One woman shared: "I worked in an actor's house for some time then worked as a bar dancer. I met my husband there and we got married. Thereafter I shifted with him in this slum area. But initially it was scary drunk men, fights, people consuming drugs, women engaging in open prostitution etc. $i$ have seen it all. But we had no choice but to live here as this house belonged to my husband. After my daughter's birth my husband changed. He stopped coming home for days together and one day I got too know that he had contracted HIV. He had also taken to drinking. In few months he died. Then I again went back to working as a housemaid in posh houses and starting stealing cash and whatever expensive things I could. I committed my first crime when my daughter was three years old. But I did because I felt that there was nothing wrong as everyone in our locality did."

Most of the women made a gradual entry into the world of crime, with property related offences like stealing mobiles, pick pocketing in local trains; while others took jobs as a house helps/ governess to commit housebreaking and thefts in jewelry shops etc. Some also took to selling liquor without license, 
drug dealing, and selling young girls in prostitution. Few of the women graduated to employing young boys to commit housebreaking in plush areas of Mumbai and stealing from construction sites etc.

\section{Factors that Augmented Entry into Crime}

One of the crucial factors that augmented their entry into crime is the influence of their peers. In some cases, due to the social milieu in which women stayed, the women perceived entry into crime as being normal and considered it justified as well.

In addition to all this, the Criminal Justice System had a major role in turning women offenders in to recidivists in crime. It was derived from the study that the police were involved in framing false cases against women. The police took the women into custody, produced them in various police stations and when the women were unable to pay the bribe demanded of them, they were falsely charged and detained, despite being picked up on suspicion alone.

The lawyers on the other hand, exploited the women by charging high fees, which the women were for obvious reasons unable to afford and this led to many women offenders getting caught in the vicious circle of crime and the Criminal Justice System. Young girls were especially exploited by lawyers. There are some lawyers who took up the cases of the young girls on the request of the judge and paid their cash bail too. However, after the girls were released from the prison, the lawyers took them to hotels and not only sexually exploited them but also threatened them not to have any relationship with any male either for companionship or marriage. In short, the lawyers were treating the girls as their keep. Due to such experiences, the women and girl offenders' hopes in the judiciary had dwindled. Women who had young children to be cared of were often willing to confess their crime but desisted from doing so due to the fear that the police would only slap several other cases on them.

Another woman shared: "My younger brother was arrested for running a matka (gambling) business. I too was taken to the police station as I would help him. Four policemen illegally detained and raped me and released me next day. They threatened to charge my brother under terrorist activities so our family had to be silent. Soon after my father got me married and we shifted to Mumbai. But before leaving for Mumbai, I lodged a complaint against those four policemen. They then traced me to Mumbai and got one police station to put false charges of house-breaking on me and threatened me to withdraw case against them. When I refused to budge the police took my custody and registered 29 cases of housebreaking against my name. Due to this my husband left me. When I got released from prison I had the responsibility of my son and daughter. So I decided to take revenge on the police by indulging in housebreaking. Now I will show them my might."

Hoping for some sort of relief or reprieve from this vicious cycle, women offenders had attempted to pour out their woes to judges while being produced in court. The judges in turn paid no heed and directed the women to communicate their woes to their lawyers. Therefore their status as offenders deprived them of access to proper legal aid or even the right to be heard in the justice system. In fact, the stakeholders in the Criminal Justice System mandated to protect the rights of the offenders, themselves exploited the women and girls and not just facilitated but have compelled their sustenance in crime. This is not to say that all individuals in Criminal Justice System exploit women offenders. But the prevalence of practices detailed above, the nexus between the different systems and the women's vulnerability by itself posing a threat to her survival in difficult circumstances leads to them to turn into recidivist.

\section{Need for Social Work Intervention}

Despite the dire circumstances of the lives of the women and the factors narrated above, there have also been cases where timely intervention has allowed for change for the better, away from the life of crime and the vicious cycle of recidivism. 
A third woman shared: "My brush with the Criminal Justice System began after I was released from the observation home. With nowhere to go and no one to care for me, I became a part of a gang that committed petty thefts. With a short respite in between, I was back again pushed by the pressure to provide for my child and a husband who suffered paralysis due to excessive consumption of alcohol. It was during one of my durations of imprisonment, a social worker reached out not only to bail me out (since my young child was all alone and could not be cared for my husband) but to extend financial support for my children's education. It's been 10 long years, and not once have I turned back to a life of crime".

However, the narration above is not a regular case in point. It is only one of the few examples of a social worker's intervention that has ensured that there was no further recidivism in the woman's life. The examples are few also because of the lack of a regular systemic intervention in the Criminal Justice System in general and for women in particular. The reason for this lies in the historical progression of social work intervention in India. The post-independence era did see a marked emphasis on social work intervention in institutional settings.

The national level social work conferences proved to be a useful platform for the exchange of knowledge, ideas and skills, as well as sharing best practices in social work intervention in the field of corrections across the country for criminal justice functionaries, government employees and social workers. However, a lot changed post the sixth Five-Year Plan. The 1980s saw a clear shift in the development paradigm in India. The honeymoon period of the people with the political class was well and truly over, and governments were being pressurized to deliver on the promise of development made to them in 1947. As a result, the focus of governance shifted from welfare to development through poverty alleviation. The State had lost faith in institutional treatment towards the social reintegration of marginalised populations. Investment in the welfare sector reduced considerably, and the fields of criminology and corrections began to shrink (Raghavan and Mishra, 2017).

In more recent times, the issue of children in conflict with law has received attention from law makers and the policy makers and there is a slow but steady talk of the need for specialized interventions in this particular area. However, the focus of law and policy makers on women as a vulnerable group is yet to draw adequate attention. Apart from gender based physical separation and few other women specific needs being met and provided for by the law, a differential treatment in terms of rehabilitation is yet to receive due consideration. However, the steadily growing graph of women's involvement in crime is a pointer for the rising emergency for social work interventions.

The social work profession is a practice-based profession and an academic discipline that promotes social change and development, social cohesion, and empowerment and liberation of people. Principles of social justice, human rights, collective responsibility and respect for diversities are central to social work. Underpinned by theories of social work, social sciences, humanities and indigenous knowledge, social work-engages people and structures to address life challenges and enhance well-being (Global Definition of Social Work, 2014). Social work is a profession dedicated to service, to social justice, and to the empowerment of vulnerable populations (National Association of Social workers [NASW], 2000). Individuals who are involved with the criminal justice system are among the most vulnerable citizens, often struggling with poverty, addiction, mental illness (James \& Glaze, 2006; Mumola \& Karberg, 2007), discrimination, and service systems that create barriers to rights and resources (Lundgren, Curtis, Oettinger, 2010).

There is an urgent need for a cadre of professional social workers in the Criminal Justice System to provide a wide continuum of services as such counselling, case interventions, providing relevant and timely information, need based interventions and above all securing the rights of the women who are entangled in the Criminal Justice System.

Professional social work can deal with the prisoners' needs for legal service, psycho-social satisfaction and rehabilitation after release from prison. Under-trials in prison need legal assistance for getting bail and convicts need it in the matter of parole and furlough. Psycho-social needs of the prisoners include emotional satisfaction and maintenance of relationship with family members (Yesudas, 2011). 
While these are the basic needs of any individual in prisons, the problems related to imprisonment become even more pronounced in the context of women inmates. Prison systems are primarily designed to cater to men and are not well equipped to address the particular needs of women in prison. As per latest data available from the end of December 2016, Indian prisons were home to 18, 498 women. Only $17 \%$ of these women live in exclusively female prisons, while the majority is housed in female enclosures of general prisons. There is national and international agreement that the condition of prisons and of women living in them needs urgent improvement (Government of India, 2018).

\section{Social Work Interventions to Prevent Recidivism among Women Offenders}

The author herself is a social worker by profession with experience of nearly ten years of work panning across the Criminal Justice System particularly with urban and rural police stations, prisons, judicial agencies such as the State and District Legal Services Authorities, civil society groups and individuals intervening in the Criminal Justice System.

Moreover, the author has been aware of a field action project of a premier school of social work in a university which has been experimenting with placement of social workers in women's sections in prisons for more than two decades and providing support to them post-release. Social work intervention with women offenders especially with regard to their children and making them selfreliant through skill based trainings has proved helpful towards their rehabilitation.

Currently the author is closely associated in facilitating and monitoring a pilot project that has allowed for the appointment of full-time Social workers across selected prison sites in Maharashtra. It is based on her professional experience that the author has been able to keenly observe the critical role that Social workers have in the prisons and eventually in the Criminal Justice System as a whole. A wide variety of challenges awaits prisoners both during their period of incarceration and post their release as well. The sheer apathy and indifference shown to prisoners by society at large, the state authorities and in some cases even their families tends to severely restrict the chances of prisoners getting over their past and leading a more fruitful and fulfilling life. Therefore social work intervention especially for the benefit of underprivileged inmates, minors, women separated from their families as well as with children of prisoners, ensuring that first time offenders can get access to justice, return to their families, and, on their release, are able to re integrate with society and lead a decent life and several more aspects of rehabilitation fall within the bandwidth of the profession. The need is to work towards a Criminal Justice System that would be more inclusive, fair and mete out meaningful justice, particularly to the marginalized and disadvantaged sections of the society.

The following section is based on learnings from the above two initiatives: Even though recidivism entails return to the prison post release, social work interventions to prevent recidivism among women need not start after women get released from prison. In fact, social work interventions with women should start the day women enter prison. Additionally, the interventions need to necessarily be both multi-layered and holistic. Physical and mental health needs, legal needs, social needs particularly fostering relationships with the family and their children, economic rehabilitation, etc. could be some of the areas of intervention, to begin with.

A model of service delivery to provide "thorough care", from prison to the community, requires the provision of services through integrated, multi-agency partnerships involving prison administrations, other governmental agencies and non-governmental agencies responsible for the delivery of treatment and welfare services. These models require the implementation of sound case management practices, usually placing a case manager as a central point for the delivery or brokerage of treatment, support and even supervision. In this regard, it is good practice for a single agency to assume the lead role in the partnership and to be responsible for coordinating the intervention. Such an arrangement is likely to assist the various partners and other stakeholders in developing a shared vision of what is to be achieved and a common language in which to better communicate with each other about the process and objectives of the programmes (UNODC, 2018). Ideally, such a programme should be a continuum from assessment of offenders' risk of re-offending, programmes to change behavior and attitudes, 
education and skill-based training, pre-release interventions to prepare women for release, to reintegration within family and society.

\section{Health Needs}

Health intervention should pay attention to physical, mental, and reproductive health needs of women. Social workers need to identify individual health problems of each of the women and ensure that they are assessed by a specialist doctor for e.g. regular check up by a gynecologist to treat women for physical, skin, sexual and reproductive problems if any so that they can avail treatment and care while in prison and return to the family and community in sound health to take care of children and family as well as be able to take on financial responsibilities if any. This will also prevent the spread of communicable diseases to families.

Many a times women who were not tobacco and gutka users before coming to prison get addicted to it while spending time in prison to cope with stress. They need to also identify women who are addicted to drugs and alcohol. Social workers need to arrange regular sessions to make them aware of the illeffects of addiction not only for their own health but its influence on children and families. They also need to arrange therapeutic counseling for women to help them. Substance abuse counselors provide a necessary support system for individuals recovering from eating disorders, drug and alcohol issues, gambling addictions, and other behavioral issues. By forming a relationship built on trust with their patients, counselors provide the support, resources, and judgement-free guidance that patients can utilize on their road to addiction recovery. Counselors can help addicts with both crisis and long-term addiction management issues, which can range from immediate medical intervention, to supporting them manage their recovery long term.

\section{Legal Awareness and Legal Aid}

Most women enter prison with little or no knowledge about the legal status of their case and no idea that they have a right to free legal aid. Majority of the women are either involved in petty crimes like thefts or simple hurt or on charge of killing their husband for demands of dowry. Legal awareness is the right of every prisoner including women but often such awareness programmes are arranged for the men prisoners as their occupancy is high compared to women. Most of the times, women get excluded from legal awareness programs due to security issues. The focus of the prison administration is to decongest the male prisons by providing maximum legal aid. Women's issues of legal aid get attention only when NGOs intervene, or social workers intervene case by case to identify the problems: no lawyer at all, private lawyer arranged by family but lawyer not representing the client, no contact between the lawyer and the woman prisoner and her family, inability to pay fees of the lawyer, inability to pay cash bail or produce sureties etc.

Recognizing these problems, social workers need to contact families to check if a lawyer has been appointed or if the woman prisoner has received the services of a free legal aid lawyer. The social worker may even have to make arrangement for the client to be produced on a video conferencing facility in prison if there is a delay in production in court. Social workers need to provide free legal aid to women who do not have lawyers by writing applications on their behalf and submitting it to the District legal services authority. Once the lawyer has been assigned, the social worker needs to regularly follow up with the lawyer to arrange meetings of the lawyer with the woman prisoner and also make home visit if required to furnish citizenship documents for securing bail from court. After receiving bail order from court, families of women prisoners need to be counseled to pay cash bail, in case of their inability to pay to due to poor economic condition, social workers may need to arrange for individuals or NGOs to pay cash bail for the woman prisoners.

\section{Skill Based Trainings and Self-employment}

Social work intervention entails organizing skill-based trainings in prison to prepare women to undertake self-employment activities post release. If possible, social workers can also arrange wagebased work for women so they earn to take care of their needs inside prison and not depend on family 
to send them money orders. Social workers can also arrange for financial literacy trainings that can help women to understand the importance of savings and also avail benefits of government schemes that can help support the education of the children.

\section{Work with Children of Women Prisoners}

Women get affected the most when their arrest leads to their separation from the children. At times, when the child is below 6 years women do keep the children with them if they have no choice. Most women prefer to leave their children back home with families or neighbours or admit them in children's institutions rather than bringing them up in the hostile environment of prisons.

Social workers play a very important role when it comes to work with children of women prisoners. During home visit if the social worker finds that the child is in a vulnerable situation outside it is important for them to immediately produce the child before Child Welfare Committee (CWC) and get the child to stay with the mother or arrange for institutionalization of the child in absence of any financial schemes to support the children. If the children's needs are taken care of, women may get time to work out alternate livelihood options as this may allow them to come out of desperation to earn for their children and wean them from taking illegal means to earn money thereby preventing recidivism.

\section{Work with police}

It is a common knowledge that police initiate Chapter cases $^{1}$ against suspected and habitual offenders under section 109 and section 110 of the Criminal Procedure Code respectively. Many a times, the police take the custody of the women offenders as soon as they get released from prison and take them to different police stations where the witnesses supposedly recognize the offenders and police use this identification as an evidence in the prosecution of the case. This results in implication of women offenders in cases where they may not be involved at all. Social workers may need to visit the police station and meet the concerned investigation officer to inform him that the social workers are working towards the rehabilitation of the woman and taking custody only on the basis of suspicion may hinder the process of rehabilitation. This assures the women offenders that they will be protected by the social workers against police exigencies. This trust building between the women offender and social worker will positively impact reformation.

While the scope of social work intervention is very broad and differs client to client, the above interventions are inter-linked and critical to prevent recidivism among women offenders.

\section{Conclusion}

The various levels of social work intervention both within and outside the prison are pre-requisites in dealing with the issue of criminality among women. The multifarious approaches will enable a more holistic treatment of the issue considering the vulnerability of women offenders both within and outside the prison, particularly post their release. Women offenders are undoubtedly entitled to have access to health, legal aid, education and skill-based trainings while serving time in prison. However, access to these basic entitlements is still a far cry. While there are a few prisons across the country making efforts to provide these facilities, their impact is yet to meet the required standards.

One of the overarching reasons for dismal performance in the rehabilitation of women is also the lack of a needs assessment that will help identify the needs and the issues of the women. The lacuna of a thorough needs assessment results in lack of identification of specific needs of women both at an individual level and as a collective group of women offenders. The assessment itself could begin with the creation of a profile of women offenders, oriented towards understanding their challenges, concerns, anxieties, and fears during incarceration and post their release etc. 
Experience has shown that all the needs of the women are interlinked and therefore need to be addressed progressively and simultaneously. But the end of the journey needs to culminate in sustained re-integration ensuring that the chances of recidivism are totally minimized. Providing legal aid to help the woman get release from the prison and securing her sound health in addition to addressing the needs of her children who are outside the prison will lead to an enhanced trust building between the women offenders and the social worker leading to better rehabilitation outcomes including prevention of recidivist tendencies among women offenders. A thorough understanding of the women in their contexts, a comprehensive and multi-layered strategy for intervention and a sustained engagement until such time that she can become self-sustained not just economically but even from a psycho-social point of view, is what will largely determine the whether she would choose pathways to commit crime and become a recidivist or stay away from the prison gates leading a more fuller and free life.

\section{References}

Bloom and Covington (2000) Bloom, Owen and Covington (2002) A Theoretical Basis for GenderResponsive Strategies in Criminal Justice, Paper presented at the American Society of Criminology Annual Meeting, Chicago, Illinois.(This article was downloaded on 05 June 2012, At: 14:27) http://www.centerforgenderandjustice.org/pdf/6.pdf

Bureau of Police Research and Development (2003) Model Prison Manual Retrieved from bprd.nic.in/WriteReadData/userfiles/file/5230647148Model\%20Prison\%20Manual.pdf on January 14, 2019. Government of India.

Cobbina, J (2009) From Prison to Home: Women's Pathways In and Out of Crime, University Of Missouri - St. Louis , B.A. Indiana University. Retrieved from https://www.ncjrs.gov/pdffiles1/nij/grants/226812.pdf on $5^{\text {th }}$ March, 2019

Crime in India (2014, 2015). Retrieved from ncrb.gov.in/ on January 14, 2019. Government of India.

Criminal Procedure Code (1973) Chapter VIII Security for keeping the peace and for good behavior. Rerieved from https://indiankanoon.org/doc/445276/ on $28^{\text {th }}$ April, 2019.

Garcia Coll et al. (1998) cited in Covington (2002) Women's journey home: Challenges for female offenders. Retrieved from https://www.stephaniecovington.com/assets/files/3.pdf on 2nd January,2019.

International Federation of Social workers. Global Definition of Social Work. (2014). Retrieved from http://www. ifsw.org/ on $28^{\text {th }}$ January, 2019.

Leverentz (2006) People, Places, and Things: The Social Process of Re-entry for Female Ex-offenders. Retrieved from https://www.ncjrs.gov/pdffiles 1/nij/grants/215178.pdf on February 18, 2019.

Lundgren, Curtis, and Oettinger (2010) Post-incarceration policies for those with criminal drug convictions: A national policy review. Families in Society: The Journal of Contemporary Human Services, 91: 31-38.

Ministry of Women and Child Development. (2018) Women in Prisons, Government of India.

Morash, Bynum, Koons (1998) Women Offenders: Programming Needs and Promising Approaches, National Instiute of Justice. Retrieved from https://www.ncjrs.gov/pdffiles/171668.pdf on 28th April, 2019.

Prison Reform Trust Briefing (2017) Why focus on reducing women's imprisonment? Retrieved from http://www.prisonreformtrust.org.uk/Portals/0/Documents/Women/whywomen.pdf on 18th February, 2019.

Raghavan and Mishra (2017). The influence of social work within the Indian criminal justice system: A critical overview. In M. D. Chong \& A. P. Francis (Eds.). Demystifying criminal justice social work in India_ (pp.3-32). New Delhi, India: Sage Publications

Ronald (2011) Social Work Intervention with Prisoners: The Case of VARHAD in Maharashtra. Rajagiri Journal of Social Development, 3 (1\&2) pp.99-108 (ISSN 0973-3086)

Sanchez and Johnson (1987) Women's journey home: Challenges for female offenders. Retrieved from https://www.stephaniecovington.com/assets/files/3.pdf on 18th February, 2019.

Tegeng and Abadi (2018) Exploring Factors Contributing to Recidivism: The Case of Dessie and Woldiya Correctional Centers. Arts Social Science Journal, Volume 9 Issue 4. 384.

The Bangkok Rules (2010) Retrieved from https://www.unodc.org/documents/justice-and-prisonreform/Bangkok_Rules_ENG_22032015.pdf on April 25, 2018. 
The Sentencing Project (2007) Women in the criminal justice system. Retrieved from https://www.sentencingproject.org/wp-content/uploads/2016/01/Women-in-the-CriminalJustice-System-Briefing-Sheets.pdf on $20^{\text {th }}$ Februray, 2019.

United Nations Office on Drugs and Crime (2018) Introductory Handbook on the Prevention of Recidivism and the Social Reintegration of Offenders. Retrieved from https://www.unodc.org/documents/justice-andprisonreform/crimeprevention/Introductory Handbook on the Prevention of Recidivism and the Social Reintegration of Offenders.pdf on 1st March, 2019.

United Nations. Standard Minimum Rules in Treatment of Prioners (Nelson Mandela Rules). (2015). Retrieved from http://www.unodc.org/documents/justice-and-prisonreform/Brochure on the UN SMRs.pdf on April 25, 2018. 